\title{
Investigation of the influence of the railroad track on the stress state of the tunnel lining
}

\author{
Mikhail Pleshko ${ }^{1 *}$, Alexei Revyakin ${ }^{2}$, and Natalia Malishevskaya ${ }^{2}$ \\ ${ }^{1}$ National University of Science and Technology MISIS (Moscow Institute of Steel and Alloys), \\ 119991, Leninskij Av., 4, Moskow, Russia \\ ${ }^{2}$ Rostov State Transport University, Sq. Rostovskogo Strelkovogo Polka Narodnogo Opolchenia, 2, \\ Rostov-on-Don, 344038, Russia
}

\begin{abstract}
Tunnel lining takes significant loads from moving vehicles. The consequences of their impact depend on the design of the railway track and the deformation characteristics of its elements. For their study, a numerical model of a circular tunnel has been developed. As a result of the model calculation, the values of the main vertical stresses in the main tunnel structures were obtained. It is established that with increasing loads from the wheel to the rail from 100 to $200 \mathrm{kN}$, the voltage on average increases by $50 \%$. The stress distribution is affected by the rigidity of the elastic layer. When it increases, the vertical stresses in the sub-rail support decrease nonlinearly, while in traveling concrete they increase nonlinearly.
\end{abstract}

\section{Introduction}

Currently, worldwide, there is a constant increase in the speed of the railway transport, the volume of freight and passenger transfers. The most important role in the development of a network of railways is played by transport tunnels that ensure the intersection of mountain and water barriers, densely built-up urban areas.

Thus, the relative length of tunnel crossings in the railroad network of Russia does not exceed $0.1 \%$, but they can significantly limit the operational characteristics of both individual sections of the track and the direction as a whole [1].

These problems are especially acute as high-speed highways develop. Currently, in Europe, the speed of freight trains in tunnels reaches $160 \mathrm{~km} / \mathrm{h}$, passenger speeds - 250 $\mathrm{km} / \mathrm{h}$ or more. The corresponding established speed of trains in tunnels in Russia does not exceed $65 \mathrm{~km} / \mathrm{h}[1]$.

The task of increasing the carrying capacity of the railway is also solved by putting into operation trains with axial loads of up to $300 \mathrm{kN}$, which necessitates an increase in the carrying capacity and reliability of the railway track construction.

A comprehensive analysis of studies of the stressed state of the ballast prism during the movement of trains with increased axial loads was carried out in $[2,3]$. It is established that the stresses in the ballast layer increase linearly with increasing train speed and axial load.

\footnotetext{
* Corresponding author: mixail-stepan@mail.ru
} 
For example, an increase in the axial load from 230 to $250 \mathrm{kN} /$ axis leads to an increase in stresses on the main track by $6.8 \%$, from 230 to $270 \mathrm{kN} / \mathrm{axis}$ - by $15.3 \%$.

With increasing loads on railroads, ballastless track designs are becoming increasingly widespread, allowing a significant increase in the reliability of the section of the railway line, reducing noise, vibration and operating costs for track maintenance $[2,3]$.

At the same time, experimental studies of stresses in the elements of the design of the ballastless path show that using a ballast-free design, the attenuation of vertical stresses occurs less intensively than in a conventional ballast design. An increase in the speed of the train from 70 to $200 \mathrm{~km} / \mathrm{h}$ causes an increase in vertical stresses on the main site of the roadbed to $20 \%$. [4].

In the tunnel, temporary loads from the rolling stock will be transferred to road concrete and lining. The stress-strain state of tunnel structures when using the ballastless path and large axial loads requires further study.

\section{Statement of the problem}

At present, two designs of the ballastless path are recommended for use in tunnels in Russia (Instruction for the application of the upper track structure in tunnels.) Ordinance No. 2607r of Russian Railways of December 18, 2012):

1. A ballastless track with sub-rail supports that are homogenized in track concrete through an elastic layer with calculated (reduced) rigidity (Fig Tunnel lining takes significant loads from moving vehicles. The consequences of their impact depend on ure 1.a).

2. The ballastless track of the "mass-spring" system with calculated (reduced) rigidity (Figure 1.b).
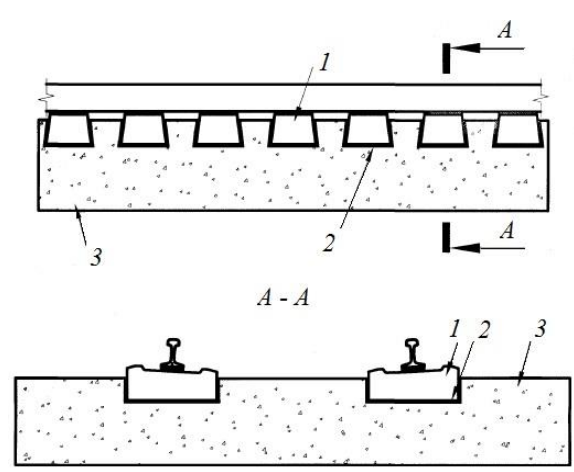

a) type I

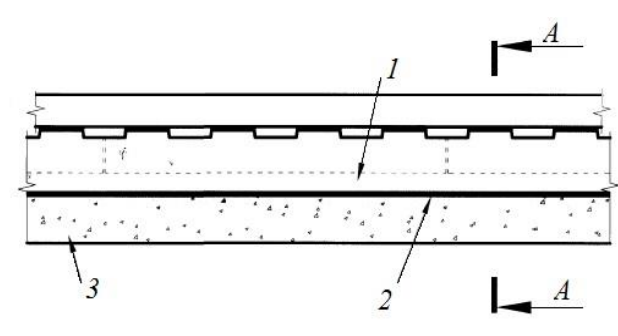

$A-A$

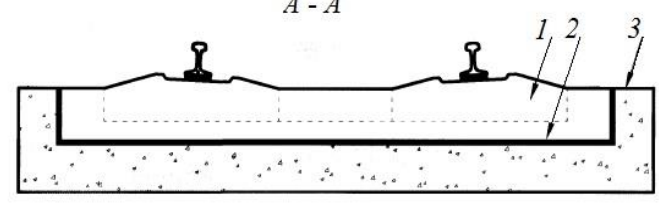

b) type II

Fig.1. Ballast-free track.

An example of a type 1 ballast-free track is LVT (Low Vibration Track) system (Figure 3), which includes rails, rail fasteners, reinforced concrete half-sleeves with rubber covers and cushioning pads, supporting the construction of the track base from unreinforced concrete. 

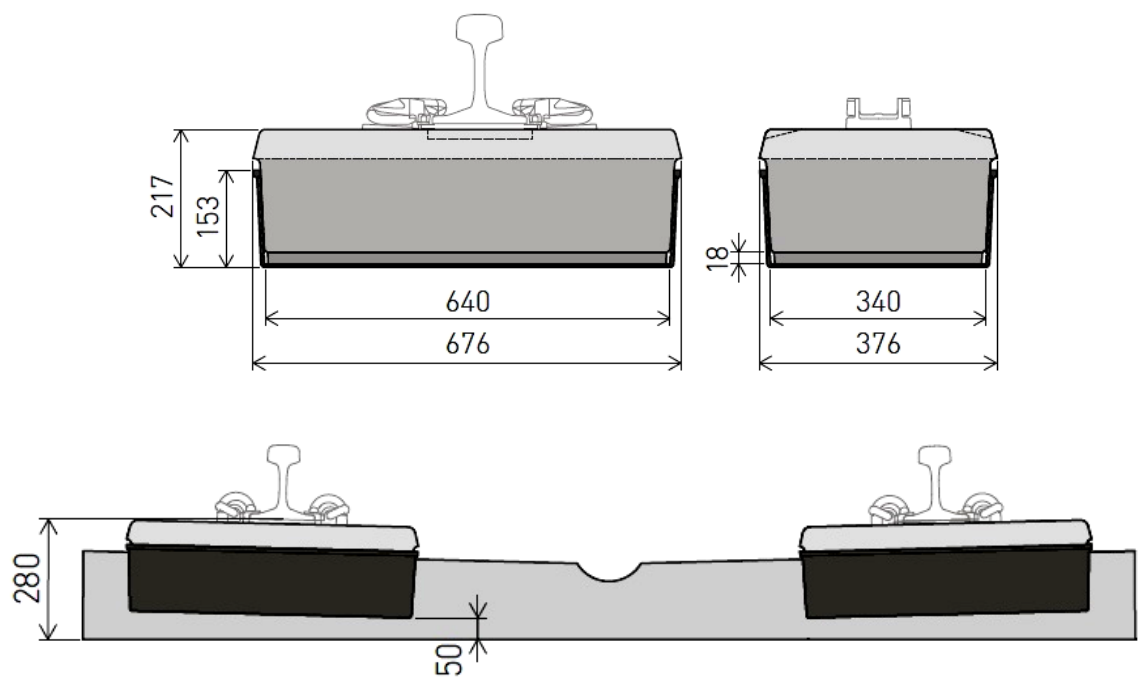

Fig. 2. Construction of ballast-free track LVT high attenuation.

The Type II constructions in particular include the Bögl and RHEDA systems (Sengeberg) (Figure 3). The structure consists of small-sized slabs of high-strength concrete or fiberreinforced concrete, an elastic layer of compliance and a rigid concrete base.

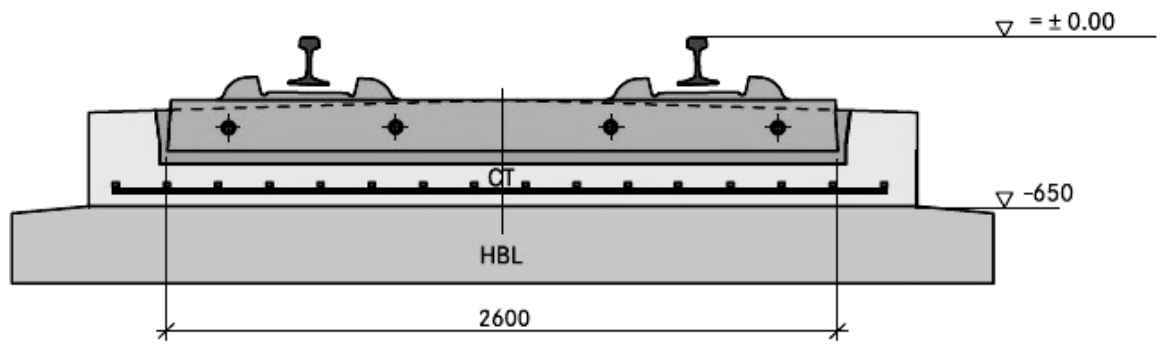

Fig. 3. Construction of ballast-free track RHEDA (Sengeberg).

It is difficult to solve such problem as railway tunnel with analytical tools. The most effective and appraisal approach is the application of method finite elements [5-10].

The possibility of usage such method for voltage analysis in ballast-free track is present in work [3] as a comparison of calculated and experimental meanings of longitudinal stresses in principal slab of ballast-free track. The limited declination has not exceeded $17 \%$.

Modeling of the railway tunnel was carried out in the program complex "Lira". A volumetric finite element model of rectangular shape with a size of $75 \times 75 \times 100 \mathrm{~m}$ was developed. The fragment of the model is shown in Fig. 5.

The railway tunnel is single-track, of circular cross-section with a radius of $3.85 \mathrm{~m}$, the thickness of the lining is $300 \mathrm{~mm}$.

The boundary conditions of the model are given in the form of constraints on the displacement of the nodes of the external faces of the model along the normal to them. A dense grid of spatial finite elements with a facet size of not more than $5 \mathrm{~cm}$ is used in the area of interest from the point of view of the set task. The faces of the end elements of the lining are assumed to be $10 \mathrm{~cm}$, surrounding the rocky ground was modeled as a net of finite elements with a size of 10 to $250 \mathrm{~cm}$ with gradual increase from the tunnel into the interior of the array [11-14]. 


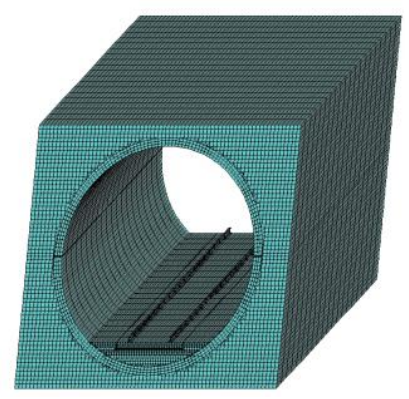

Fig. 5. Fragment of the volume finite element model of the railway tunnel.

As the upper structure of the path, a type II ballastless path was adopted (Fig. 1b).

The physical and mechanical characteristics of the materials of the model are presented in Table. 1.

Table 1. Physical and mechanical characteristics of the materials of the model.

\begin{tabular}{|l|c|c|c|}
\hline \multicolumn{1}{|c|}{ Type of feature } & $\begin{array}{c}\text { Initial modulus of } \\
\text { elasticity, MPa } 10^{-3}\end{array}$ & $\begin{array}{c}\text { Specific } \\
\text { volumetric } \\
\text { weight, } \mathrm{kN} / \mathrm{m}^{3}\end{array}$ & $\begin{array}{c}\text { The coefficient of } \\
\text { transverse } \\
\text { deformation }\end{array}$ \\
\hline Rail P65 & 210 & 78 & 0,3 \\
\hline Sub-rail support B40 & 36 & 25 & 0,2 \\
\hline The elastic laye & 2 & 18 & 0,4 \\
\hline Track concrete B15 & 24 & 25 & 0,2 \\
\hline Lining (concrete B35) & 34,5 & 25 & 0,2 \\
\hline Rock mass & 15 & 27 & 0,3 \\
\hline
\end{tabular}

To assess the impact of temporary loads on the rolling stock on the stress state of the tunnel structures, the model was loaded only with concentrated loads from the wagon wheels to the rail.

The vertical dynamic load of the wheel on the rail was from expression

$$
P_{\partial u н}^{\max }=P_{\mathrm{cp}}+\lambda S,
$$

where $\lambda$ is a normalized factor determining the probability of occurrence of a dynamic load; $S$ is the mean square deviation of dynamic wheel dynamic stress on the rail;

$P_{\mathrm{cp}}$ - average value of the vertical load on the rail, $\mathrm{kN}$ :

$$
P_{c p}=P_{\text {cт }}+0,75 P_{\mathrm{p}}^{\max },
$$

Here $P_{\text {ст }}$ - static load of a wheel on a rail, $\mathrm{\kappa H}$;

$\mathrm{P}_{\mathrm{p}}{ }^{\max }$ is the dynamic maximum load of the wheel on the rail, which arises from the oscillation of the body on the springs, $\mathrm{kN}$.

\section{Results}

As a result of calculations for various axial loads, the values of the main vertical stresses in the main elements of the tunnel structures were obtained. In Fig. 6 shows an example of a section of a tunnel with isopoles of principal vertical stresses. Data on the calculated values of the maximum vertical stresses in the main tunnel structures are presented in Table. 2. 


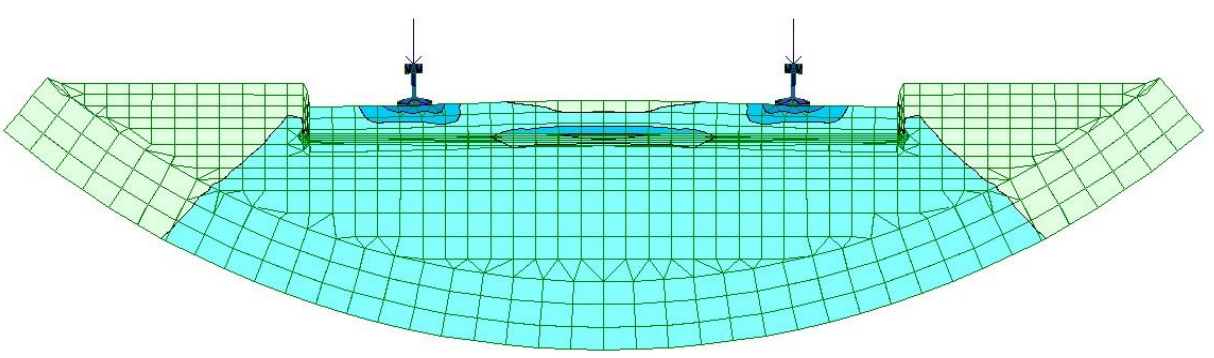

Fig. 6. Fragment of the section of the model with isopoles of principal vertical stresses.

Table 2. Results of calculation of vertical stresses in tunnel structures

\begin{tabular}{|l|c|c|c|c|c|}
\hline \multirow{2}{*}{ Type of feature } & \multicolumn{6}{|c|}{$\begin{array}{l}\text { The main vertical stresses, } \mathrm{kPa} \text {, with the value of the vertical } \\
\text { dynamic load of the wheel on the rail, } \mathrm{kN}\end{array}$} \\
\cline { 2 - 6 } & 100 & 125 & 150 & 175 & 200 \\
\hline Under-rail support & 932,5 & 1170,0 & 1339,0 & 1631,9 & 1865,0 \\
\hline Track concrete B15 & 80,3 & 100,3 & 120,4 & 140,5 & 160,5 \\
\hline Lining (concrete B35 & 65,6 & 82,0 & 98,4 & 114,9 & 131,3 \\
\hline
\end{tabular}

The results of the calculations show that with an increase in the vertical load from 100 to $200 \mathrm{kN}$, the vertical stresses in tunnel structures increase by an average of $50 \%$. At the elastic stage of the deformation of materials, the dependence of the stresses on the load is linear.

Of particular interest is the investigation of the influence of the rigidity of the elastic layer on the stresses in the constructions of the ballastless path. The stiffness of the elastic layer can be determined from expression

$$
H=E \frac{A}{h},
$$

where $E$ is the modulus of elasticity of the layer, GPa;

$H$ is the area of the elastic layer in terms of 1 p.m. of path, $\mathrm{m} 2$;

$h$ is the thickness of the elastic layer, $\mathrm{m}$.

In Fig. 7a shows the dependence of the main vertical stresses in the subrace rail on the rigidity of the elastic layer. In Fig. 8a shows a similar dependeig. 7 - Dependences of the main vertical stresses on the rigidity of the elastic layer:

$\mathrm{a}$ - in the subrace rail; $\mathrm{b}$ - in track concrete 


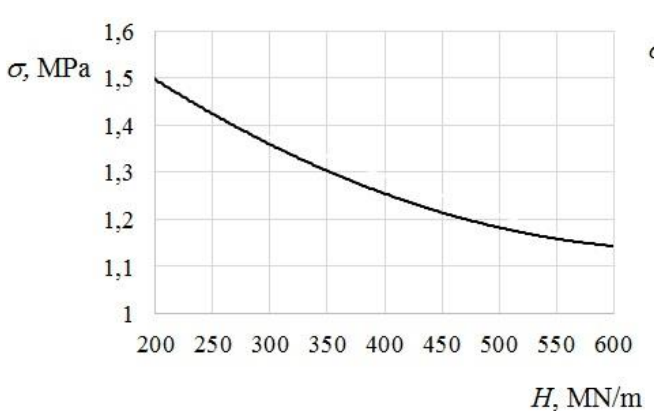

a

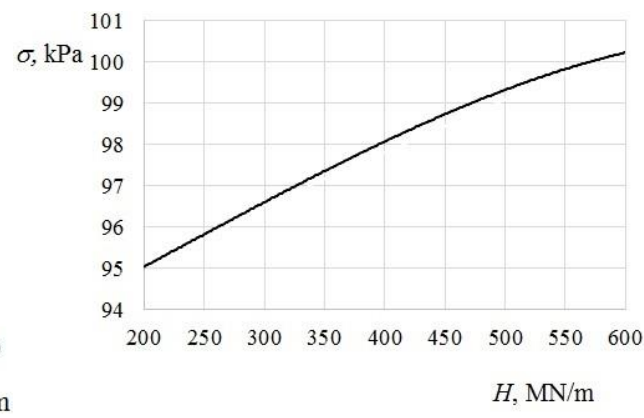

b

Fig. 7. Dependences of the main vertical stresses on the rigidity of the elastic layer: $\mathrm{a}$ - in the subrace rail; $\mathrm{b}$ - in track concrete.

\section{Conclusions}

The received results testify expediency at designing of designs of a railway tunnel of carrying out of the analysis of a multicomponent system «a mobile structure - a rail way the road concrete - a lining - a ground». Its analysis under the action of calculated combinations of permanent, temporary and special loads will allow to determine the required strength and deformation parameters of structures and to increase the technical and economic indicators of design solutions. The rigidity of the elastic layer can be considered as one of the regulating elements for achieving optimal parameters of the system interaction under severe operating conditions.

\section{References}

1. Yu.S. Frolov, Transport of the Russian Federation, 1(26) (2010)

2. G. Michas, Slab track system for High, Speed railways, Royal Institute of Technology (KTH). Sweden, Stockholm (2012)

3. S.Y. Jang, H.S. Lee, Development of prefabricate concrete slab track system and trial installation on revenue line, (South Korea, Uiwang 2008)

4. A.F. Kolos, Z.E. Mirsalikhov, Inženernyj vestnik Dona (Rus), 3 (2012)

5. N.M. Bykova, D.A. Zainagabdinov, Modern technologies. System analysis. Modeling, 1(13) (2007)

6. M.S. Pleshko, Y.V. Vcherashnyaya, A.A. Nasonov, Gornyi Zhurnal, 10 (2016)

7. M.S. Pleshko, et.al. ARPN Journal of Engineering and Applied Sciences, 10(1) (2015)

8. M.S. Pleshko, O.V. Pashkova, A.A. Nasonov, Gornyi Zhurnal, 3 (2015)

9. M. Pleshko, B. Meskhi, M. Pleshko, MATEC Web of Conferences, 170, 03023 (2018)

10. B. Meskhi, M. Pleshko, et.al. Earth and Environmental Science, 90(1), 012217 (2017)

11. M. Pleshko, A. Pankratenko, A. Revyakin, E. Shchekina, S. Kholodova, E3S Web of Conferences, 33, 02036 (2018)

12. G. Romanova, M. Pleshko, M. Rossinskaya, N. Saveleva, A. Pankratenko, Advances in Intelligent Systems and Computing, 692 (2018)

13. M. Pleshko, I. Voinov, MATEC Web of Conferences, 106, 05004 (2017)

14. A. Pankratenko, et.al. MATEC Web of Conferences, 7, 02026 (2018) 